\title{
Conotoxins: Possible Therapeutic Measure for Huntingtons Disease
}

\section{Pallavi Bhosle* and Sawarkar Vaibhav}

Department of Pharmacology, Sinhgad College of Pharmacy and Post Graduate Research centre, Vadgaon, University of Pune, Maharashtra, India

\begin{abstract}
Huntington's disease (HD) is a genetic disorder with autosomal dominant inheritance with progressive degeneration of neurons. It is characterized by affective, cognitive, behavioral, and motor dysfunctions. 3 nitropropionic acid is well established animal model which initiates a complex series of neurochemical and signaling changes that lead to pathological events including neuronal excitotoxicity by excessive glutamate release, neuroinflammation and energy impairment. Excitotoxins like NMDA and kainic acid which binds to these receptors to release high levels of glutamate that can cause excitotoxicity by allowing high levels of calcium ions $\left(\mathrm{Ca}^{2+}\right)$ to enter the cell. $\mathrm{Ca}^{2+}$ influx into cells activates a number of enzymes, including phospholipases, endonucleases, and proteases such as calpain. These enzymes increase apoptosis, oxidative stress and energy impairment thereby causing mitochondrial dysfunctions and go on to damage neuronal structures. The toxic venom used by the cone shells called conotoxin contains up to 50 different peptides that selectively inhibit the function of ion channels and excitatory amino acid receptors such as NMDA involved in the transmission of nerve signals in animals representing an extensive array of ion channel blockers each showing a high degree of selectivity for particular types of channels. Conotoxins selectively target a range of ion channels and NMDA receptors, making them widely useful tool for probing nervous system function. Here we hypothize the protective effect of conotoxins, from genus Conus geographus named w-conotoxin and conantoxin, against excitotoxic neuronal cell death using 3 NP induced Huntington's model.
\end{abstract}

Keywords: Huntington's disease (HD); Neurodegeneration; Excitotoxicity; Conopeptides; Conotoxins; NMDA; 3 Nitropropionic acid

\section{Introduction}

Huntington's disease (HD) is a genetic disorder with autosomal dominant inheritance with progressive degeneration of neurons. It is characterized by affective, cognitive, behavioral, and motor dysfunctions preferentially due to morphological abnormalities and cell death of the striate medium-sized spiny neurons. 3-Nitropropionic acid (3-NP), a neurotoxin irreversibly inhibits succinate dehydrogenase enzyme (complex-II) in the electron transport chain and produces HD like symptoms both in animals and human [1]. 3-NP intoxication leads to selective striate lesions which begin in the striatum and later spread to the entire brain [2]. Studies reported that 3-NP treatment significantly causes oxidative damage in diverse areas of brain particularly striatum. Possible source of oxidative damage in 3-NP model is impairment of mitochondrial energy production (inhibition of complex-II) [3,4]. Excitotoxicity contributes to the pathogenesis of HD $[5,6]$. Studies in both rodents and primates show striking similarities between striatal lesions produced by N-MethylD-Aspartate (NMDA) agonists and the neurochemical and histologic features of HD [7-10], that causes an increase in oxygen flux through mitochondria, leading to elevated ROS production $[5,11]$.

Conus species i.e conus goegraphus contains a unique set of peptides in their venom specifically $\omega$ (omega)-conotoxin and conantokins. These predatory marine snails (cone shells) inject this potent cocktail of peptide toxins into their prey to immobilise them $[12,13]$. The toxic venom used by the cone shells contains up to 50 different peptides that selectively inhibit the function of voltage gated $\mathrm{N}$ type of $\mathrm{Ca}^{++}$ion channels involved in the transmission of nerve signals in animals and antagonizes the function of NMDA receptors $[14,15]$. So these toxins that are used for defence by animal could be isolated, tested and used for various pharmacological and physiological activities. This hypothesis focuses the properties of conopeptides [16] and to use them as drug leads for the development of novel therapeutics for the treatment of Huntington's disease (HD) occurring due to glutamate toxicity.

\section{Conotoxins}

Venomous animals have evolved a vast array of peptide toxins for prey capture and defence. These predatory animals have devised their efficient venom apparatus that allows them to successfully capture polychaete worms, molluscs or in some cases fish as their primary food sources [12]. Marine cone snails from the genus Conus are estimated to consist of up to 700 species. They have been previously grouped into superfamilies according to signal sequence and into families based on their cysteine framework and biological target [13]. The number of conotoxins whose activities have been determined and they are called the $\alpha$ (alpha)-, $\delta$ (delta)-, $\kappa($ kappa)-, $\mu(\mathrm{mu})$-, conantokins and $\omega$ (omega)-types. The high specificity exhibited by these novel compounds for neuronal receptors and ion channels in the brain and nervous system indicates the high degree of selectivity that this class of neuropeptides can be expected to show when used therapeutically in humans.

Each of the types of conotoxins attacks a different ion channel. $a$-conotoxin inhibits nicotinic acetylcholine receptors at nerves and muscles. $\delta$-conotoxin inhibits the inactivation of voltage-dependent sodium channels. $\kappa$-conotoxin inhibits potassium channels. $\mu$-conotoxin inhibits voltage-dependent sodium channels in muscles. $\omega$-conotoxin inhibits $\mathrm{N}$-type voltage-dependent calcium channels [12-14]. N-type voltage-dependent calcium channels are located in the pain and excitatory amino acid receptors of the nervous system, $\omega$-conotoxin are inhibitors of voltage gated $\mathrm{Ca}^{++}$channels and also

*Corresponding author: Pallavi Bhosle, Sinhgad Education Socitiety's, Sinhgad College of Pharmacy and Post Graduate Research Centre, Survey no. 44/1, off Sinhgad road, Vadgaon (BK), Pune, 411041, Maharashtra, India, E-mail: pallavi.1230@gmail.com

Received July 30, 2013; Accepted August 23, 2013; Published August 26, 2013

Citation: Bhosle P, Vaibhav S (2013) Conotoxins: Possible Therapeutic Measure for Huntingtons Disease. J Neurol Disord 1: 129. doi:10.4172/2329-6895.1000129

Copyright: ( 2013 Bhosle $P$, et al. This is an open-access article distributed under the terms of the Creative Commons Attribution License, which permits unrestricted use, distribution, and reproduction in any medium, provided the original author and source are credited. 
has an analgesic effect, whereas conantokins are antagonists of $\mathrm{NMDA}$ (an excitatory amino acid) receptor $[4,14]$. These $\omega$-conotoxin and conantokins are reported to reduce glutamate toxicity $[4,17]$.

\section{Purification of conopeptides}

Conotoxins are multiple disulfide-bonded peptides isolated from marine cone snail venom. These toxins have been classified into several families based on their disulfide pattern and biological properties. The venom of cone snails can be extracted from their venom glands. The peptides from conotoxins from conotoxins can be separated and eluted by reverse phase HPLC. The molecular masses of the peptide scan are determined by electro spray ionization mass spectrometry. Further purification and synthesis of peptides can be done by solid phase peptide synthesis method and amino acid analysis can be done by amino acid analyzer followed perhaps by NMR-based structure determination [18].

The chemical re-engineering of these via cyclization has been particularly valuable in improving their biopharmaceutical properties. A variety of other chemical re-engineering approaches have also been used. Minor re-engineering of $x$-conotoxin MrIa to convert its $\mathrm{N}$-terminal residue to pyroglutamic acid proved particularly successful and the modified derivative, Xen2174, is currently in clinical trials for neuropathic pain. A lead compound, ACV1 (conotoxin Vc1.1 from Conus victoriae), has entered Phase II clinical trials and is being developed for the treatment for neuropathic pain. ACV1 will be targeted initially for the treatment of sciatica, shingles and diabetic neuropathy. The compound is a 16 amino acid peptide a novel alpha-conotoxin identified by gene sequencing, an antagonist of neuronal nicotinic acetylcholine receptors is active in suppressing the vascular response to selective stimulation of sensory nerves in vivo [19].

\section{The rationale for the role of excitotoxicity in the pathogenesis of Huntington's disease}

Excitatory synaptic transmission in the mammalian CNS is principally mediated by L-glutamate. Glutamate is the major excitatory transmitter in the brain. Glutamate information which regulates brain development and that determines cellular survival, differentiation and elimination as well as formation and elimination of nerve contacts (synapses) [17,20]. Glutamate interacts with at least three classes of membrane receptors, each commonly referred to by preferred pharmacological agonists: $\mathrm{N}$-methyl-o-aspartate (NMDA), quisqualate, and kainate [21]. These three classes are linked to membrane cation channels. A normal cellular uptake mechanism removes excess glutamate from the extracellular space $[22,23]$. The toxic changes produced by glutamate or related excitatory amino acids in vivo are of two sorts: possibly corresponding to the acute swelling and delayed degeneration observed in vivo [24]. The first component, marked by acute neuronal swelling, depends on extracellular $\mathrm{Na}^{+}$ and $\mathrm{Cl}^{-}$and can be mimicked by other depolarizing agents [25]. The second component, marked by delayed neuronal degeneration, depends on extracellular $\mathrm{Ca}^{++}$and may be thus mediated by the toxic effects produced by excessive $\mathrm{Ca}^{++}$influx $[22,24,25]$. Glutamateinduced $\mathrm{Ca}^{2+}$ accumulation by cortical neurons is closely correlated with resultant neuronal degeneration [26]. There is no proven effective therapy for Huntington's disease exists, It will be important to determine whether certain more effective treatments or have fewer side effects than others in disease states might be good approach to enhance the disease tolerance. NMDA receptor antagonist could be beneficial neuroprotective agents or ion channel blockers which inhibit glutamate-induced translocation of protein kinase $\mathrm{C}$ and thereby reducing exitotoxic neuronal cell death $[4,20,27]$.

\section{Hypothesis}

Currently, there is no therapy available which can stop or postpone huntingtons disease. We can only slow down the progression of the disease. Though it is unexplained why the mutation of gene takes place and other mechanisms related to it, the facts like oxidative stress, exitotoxicity and mitochondrial dysfunctions leads to the fatal behavioural, motar and cognitive manifestations of the disease. Although many therapies have been proposed for the treatment, there is no therapy which can entirely cure this disease. Whereas, there are some therapies which give symptomatic relief or minimize the oxidative stress of the body and that almost all of them have considerable shortcomings. There is need to find out some more potent treatment that could reduce the neuronal cell death. Our literature review showed that $\omega$-conotoxin and conantokins acts as the NMDA receptor antagonists as well as reduces the $\mathrm{Ca}++$ signaling and extracellular glutamate release and thereby minimizing excitotoxicity, mitochondrial dysfunctions and energy impairments, enhancing the life span of neurons. On the basis of this approach the studies on the animal model of Huntington's disease could be performed. If this hypothesis is shown to be effective, through preclinical studies, it would have important implications for management of Huntington's disease as well as many other neurodegenerative diseases.

\section{Evaluation of hypothesis}

Series of neurochemical, neurophysiological and structural abnormalities are observed in the CNS due to HD. The prominent manifestations seen in Huntington's disease are cognition impairment due to neurodegeneration with loss of working memory, choreoforms, loss in coordination and balance, slurred speech and difficulty in writing. All these abnormalities are due to decreased succinate levels and increased lactate levels. Many emotional changes occur during progression of the disease in which depression and irritability are prominent psychiatric symptoms [28]. Evaluation of hypothesis can be done by estimating behavioral and biochemical parameters like muscular grip strength using rotarod apperatus, locomotar activity. Cognition impairement is evaluated by morris water maize. In huntington's disease biochemical enzymes in the brain are majorly hampered. Estimating levels of the enzymes may be useful to check the effectiveness of the treatment. Biochemical parameters like succinate dehydrogenase activity, lactate dehydrogenase activity, Oxidative stress parameters such as MDA, NO, catalase, SOD activity are the important aspects that may be useful in the evaluation of the hypothesis. Detailed description of the methods to evaluate conotoxins against animal model of huntingtons diseases are given below.

\section{Rotarod activity}

Motor in coordination and grip strength was assessed by using rotarod apparatus (Techno, Ambala, India). Animals were exposed to prior training session to acclimatize them on rotarod before starts the actual assessing of drug treatment. Animals were placed on the rotating rod with a diameter of $7 \mathrm{~cm}$ (speed $25 \mathrm{rpm}$ ). The cut off time was $180 \mathrm{~s}$. Three separate trials after 5 min gap were given to each rat. The average fall of time was recorded and expressed as count per 5 $\min [29]$.

\section{Assessment of gross behavioral activity (locomotor activity)}

The locomotor activity was monitored by using actophotometer 
(IMCORP, Ambala, India). The motor activity in actophotometer was detected by infrared photo cells installed in the instrument. Animals were placed individually in the activity chamber for $3 \mathrm{~min}$ as a habituation period before making actual recording. Each animal was observed over a period of $5 \mathrm{~min}$ and expressed as counts per $5 \mathrm{~min}$ [30].

\section{Morris water maze test}

The acquisition and retention of a spatial navigation task was examined using Morris water maze [5]. Animals were trained to swim in circular pool $(180 \mathrm{~cm}$ diameter $\times 60 \mathrm{~cm}$ height $)$ located in a test room. The pool was filled with water $\left(28 \pm 2^{\circ} \mathrm{C}\right)$ to a depth of $40 \mathrm{~cm}$. A movable circular platform $9 \mathrm{~cm}$ in diameter, mounted on a column was placed in the pool $1 \mathrm{~cm}$ above the water level formaze acquisition test. The platform was fixed in the center of any one of the 4 quadrants and remained in that location for the duration of the experiment. Animals received a training session consisting of 4 trials in each session for 4 days, starting from the first day of 3-NP administration. In all 4 trials, starting positions were different. The latency to find the platform was recorded up to a maximum of $2 \mathrm{~min}$. The time taken (latency) to reach the platform on the $5^{\text {th }}$ day was recorded as initial acquisition latency. On the $10^{\text {th }}$ and $15^{\text {th }}$ day, the plat form was removed. Each animal was randomly released from any one of the edges $(\mathrm{N}, \mathrm{S}, \mathrm{E}, \mathrm{W})$ facing the wall of the pool. The time taken to reach the quadrant where platform was placed was recorded.

\section{Measurement of Oxidative Stress Parameters}

\section{Measurement of lipid peroxidation}

The quantitative measurement of lipid peroxidation in striatum was performed according to the method of Wills [31]. The amount of malondialdehyde (MDA), a measure of lipid peroxidation was measured by reaction with thiobarbituric acid at $532 \mathrm{~nm}$ using Perkin Elmer lambda 20 on spectrophotometer (Norwalk, CT, USA). The values were calculated using molar extinction coefficient of chromophore $\left(1.56 \times 10^{5} \mathrm{M}^{-1} \mathrm{~cm}^{-1}\right)$ and expressed as percentage of vehicle treated group.

\section{Estimation of nitrite}

The accumulation of nitrite in the supernatant, an indicator of the production of nitric oxide (NO), was determined with a colorimetric assay with Greiss reagent $(0.1 \% \mathrm{~N}$-(1-naphthyl) ethylenediame dihydrochloride, $1 \%$ sulfanilamide and $2.5 \%$ phosphoric acid) as described by Green et al. [32]. Equal volumes of supernatant and Greiss reagent were mixed, and incubated for $10 \mathrm{~min}$ at room temperature. The absorbance of each sample was determined at $540 \mathrm{~nm}$ at Perkin Elmer lambda 20 spectrophotometer. The concentration of nitrite in the supernatants was determined from a sodium nitrite standard curve and expressed as percentage of vehicle treated group.

\section{Catalase estimation}

Catalase activity was assayed by the method of Luck [33], wherein breakdown of hydrogen peroxides $\left(\mathrm{H}_{2} \mathrm{O}_{2}\right)$ is measured at $240 \mathrm{~nm}$. Briefly, assay mixture consisted of $3 \mathrm{ml}$ of $\mathrm{H}_{2} \mathrm{O}_{2}$ phosphate buffer and $0.05 \mathrm{ml}$ of supernatant of tissue homogenate (10\%), and change in absorbance of each sample was recorded at $240 \mathrm{~nm}$. The results were expressed as micromole $\mathrm{H}_{2} \mathrm{O}_{2}$ decomposed per milligram of protein/ $\min$.

\section{Superoxide dismutase activity (SOD)}

SOD activity was assayed according to the method of cono [34] where in reduction of nitrazobluetetrazolium (NBT) was inhibited by the SOD is measured at $560 \mathrm{~nm}$ using spectrophotometer. Briefly, reaction was initiated by the addition of the hydroxylamine hydrochloride to the mixture containing NBT and sample. The results were expressed as unit/mg protein.

\section{Succinate dehydrogenase (SDH) activity (Complex-II)}

SDH was measured spectrophotometrically according to King [35]. The method involves oxidation of succinate by an artificial electron acceptor, potassium ferricyanide. The reaction mixture contained $0.2 \mathrm{M}$ phosphate buffer $\mathrm{pH} 7.8,1 \% \mathrm{BSA}, 0.6 \mathrm{M}$ succinic acid, and $0.03 \mathrm{M}$ potassium ferricyanide. The reaction was initiated by the addition of mitochondrial sample and change in absorbance was recorded at $420 \mathrm{~nm}$.

\section{Lactate dehydrogenase enzyme activity}

The Lactate dehydrogenase enzyme activity was estimated by the method of King [35]. The reaction mixture contained $0.5 \mathrm{ml}$ of buffered substrate made in $0.1 \mathrm{M}$ glycine buffer ( $\mathrm{pH} 7.9$ ) and $0.1 \mathrm{ml}$ of tissue homogenate. The tubes were allowed to be incubated for $30 \mathrm{~min}$ at $37^{\circ} \mathrm{C}$. Finally, the color was intensified by the addition of $5.0 \mathrm{ml}$ of $0.4 \mathrm{~N} \mathrm{NaOH}$. The absorbance was read at $440 \mathrm{~nm}$. The activity was expressed as pyruvate formed $/ \mathrm{min} / \mathrm{mg}$ protein.

\section{Statistical analysis}

The data was analyzed by using analysis of variance (ANOVA) followed by Tukey's test. All the values are expressed as mean \pm S.E.M. In all tests, the criterion for statistical significance was $\mathrm{P}<0.05$.

\section{Conclusion}

Huntingtons disease causes neurodegeneration due to excitotoxicity and mitochondrial dysfunction. The key role of Conotoxins in reducing $\mathrm{Ca} 2+$ influx and NMDA receptor antagonism thereby reducing glutamate excitotoxicity could be important consideration as therapeutics. So this hypothesis suggests the animal studies of conotoxin against 3 nitropropionic acid induced huntingtons model. Once validated, Conotoxins may serve as a target drugs in HD management.

\section{Acknowledgment}

Authors gratefully acknowledged the support of the Sinhgad technical education society, vadgaon, pune for constant support and motivation.

\section{Conflict of Interest}

There are no any conflicts of interest.

\section{References}

1. Kumar P, Kalonia H, Kumar A (2009) Sesamol attenuate 3-nitropropionic acid-induced Huntington-like behavioral, biochemical, and cellular alterations in rats. J Asian Nat Prod Res 11: 439-450.

2. Alexi T, Hughes PE, Faull RL, Williams CE (1998) 3-Nitropropionic acid's lethal triplet: cooperative pathways of neurodegeneration. Neuroreport 9: R57-64.

3. Beal MF, Brouillet E, Jenkins BG, Ferrante RJ, Kowall NW, et al. (1993) Neurochemical and histologic characterization of striatal excitotoxic lesions produced by the mitochondrial toxin 3-nitropropionic acid. J Neurosci 13: 4181-4192.

4. Alex AB, Saunders GW, Dalpé-Charron A, Reilly CA, Wilcox KS (2011) CGX1007 prevents excitotoxic cell death via actions at multiple types of NMDA receptors. Neurotoxicology 32: 392-399.

5. Kumar P, Kumar A (2009) Possible neuroprotective effect of Withania somnifera root extract against 3-nitropropionic acid-induced behavioral biochemical, and mitochondrial dysfunction in an animal model of Huntington's disease. J Med Food 12: 591-600. 
Citation: Bhosle P, Vaibhav S (2013) Conotoxins: Possible Therapeutic Measure for Huntingtons Disease. J Neurol Disord 1: 129. doi:10.4172/23296895.1000129

6. Beal MF (1992) Does impairment of energy metabolism result in excitotoxic neuronal death in neurodegenerative illnesses? Ann Neurol 31: 119-130.

7. Albin RL, Greenamyre JT (1992) Alternative excitotoxic hypotheses. Neurology 42: 733-738.

8. Beal MF, Ferrante RJ, Swartz KJ, Kowall NW (1991) Chronic quinolinic acid lesions in rats closely resemble Huntington's disease. J Neurosci 11: 16491659.

9. Beal MF, Kowall NW, Ellison DW, Mazurek MF, Swartz KJ, et al. (1986) Replication of the neurochemical characteristics of Huntington's disease by quinolinic acid. Nature 321: 168-171.

10. Young AB, Greenamyre JT, Hollingsworth Z, Albin R, D'Amato C, et al. (1988) NMDA receptor losses in putamen from patients with Huntington's disease. Science 241: 981-983.

11. Beal MF (2000) Energetics in the pathogenesis of neurodegenerative diseases. Trends Neurosci 23: 298-304.

12. Lewis RJ, Garcia ML (2003) Therapeutic potential of venom peptides. Nat Rev Drug Discov 2: 790-802.

13. Livett BG, Gayler KR, Khalil Z (2004) Drugs from the sea: conopeptides as potential therapeutics. Curr Med Chem 11: 1715-1723.

14. Adams DJ, Alewood PF, Craik DJ, Drinkwater RD, Lewis RJ (1999) Conotoxins and Their Potential Pharmaceutical Applications, Drug Devel Res 46: 219-234.

15. Adams DJ, Berecki G (2013) Mechanisms of conotoxin inhibition of N-type $(\mathrm{Ca}(\mathrm{v}) 2.2)$ calcium channels. Biochim Biophys Acta 1828: 1619-1628.

16. Alonso D, Khalil Z, Satkunanthan N, Livett BG (2003) Drugs from the sea: conotoxins as drug leads for neuropathic pain and other neurological conditions. Mini Rev Med Chem 3: 785-787.

17. Platt RJ, Han TS, Green BR, Smith MD, Skalicky J, et al. (2012) Stapling mimics noncovalent interactions of $\hat{i}^{3}$-carboxyglutamates in conantokins, peptidic antagonists of N-methyl-D-aspartic acid receptors. J Biol Chem 287: 20727-20736.

18. Baby J, Sheeja SR, Jeevitha MV, Ajisha SU, Jini D (2011) Conotoxins: a potential natural therapeutic for pain relief. Int J Pharm Pharm Sci 3: 1-5.

19. Carstens BB, Clark RJ, Daly NL, Harvey PJ, Kaas Q, et al. (2011) Engineering of conotoxins for the treatment of pain. Curr Pharm Des 17: 4242-4253.

20. Layer RT, Wagstaff JD, White HS (2004) Conantokins: peptide antagonists of NMDA receptors. Curr Med Chem 11: 3073-3084.
21. Watkins JC, Olverman $H$ (1988) Agonists and antagonists for excitatory amino acid receptors. Trends Neurosci 10: 265-272.

22. Weiss JH, Choi DW (1988) Beta-N-methylamino-L-alanine neurotoxicity: requirement for bicarbonate as a cofactor. Science 241: 973-975.

23. Schousboe A (1981) Transport and metabolism of glutamate and GABA in neurons are glial cells. Int Rev Neurobiol 22: 1-45.

24. Weiss J, Goldberg MP, Choi DW (1986) Ketamine protects cultured neocortical neurons from hypoxic injury. Brain Res 380: 186-190.

25. Olney JW, Price MT, Samson L, Labruyere J (1986) The role of specific ions in glutamate neurotoxicity. Neurosci Lett 65: 65-71.

26. Choi EJ, Ahn WS (2008) Neuroprotective effects of chronic hesperetin administration in mice. Arch Pharm Res 31: 1457-1462.

27. Marcoux FW, Goodrich JE, Probert AW, Dominick MA (1988) Ketamine prevents glutamate-induced calcium influx and ischemia nerve cell injury. In Sigma and Phencyclidine-like Compounds as Molecular Probes in Biology, Ann Arbor: NPP Books.

28. Naarding P, Kremer HP, Zitman FG (2001) Huntington's disease: a review of the literature on prevalence and treatment of neuropsychiatric phenomena. Eur Psychiatry 16: 439-445.

29. Kumar P, Kumar A (2009) Neuroprotective effect of cyclosporine and FK506 against 3-nitropropionic acid induced cognitive dysfunction and glutathione redox in rat: possible role of nitric oxide. Neurosci Res 63: 302-314.

30. Kumar P, Padi SS, Naidu PS, Kumar A (2007) Cyclooxygenase inhibition attenuates 3-nitropropionic acid-induced neurotoxicity in rats: possible antioxidant mechanisms. Fundam Clin Pharmacol 21: 297-306.

31. Wills ED (1966) Mechanisms of lipid peroxide formation in animal tissues Biochem J 99: 667-676.

32. Green LC, Wagner DA, Glogowski J, Skipper PL, Wishnok JS, et al. (1982 Analysis of nitrate, nitrite, and [15N]nitrate in biological fluids. Anal Biochem 126: $131-138$.

33. Luck H (1971) Catalase. In: Bergmeyer HU (Ed.), Methods of enzymatic analysis. New York: Academic Press.

34. Kono $Y$ (1978) Generation of superoxide radical during autoxidation of hydroxylamine and an assay for superoxide dismutase. Arch Biochem Biophys 186: 189-195

35. King TE, Howard RL (1967) Preparations and properties of soluble NADH dehydrogenases from cardiac muscle. Methods Enzymol 10: 275-284. 